\title{
EL SISTEMA TURÍSTICO DE LA COMUNIDAD DE COPAL, NICOYA, GUANACASTE, COSTA RICA. UN DIAGNÓSTICO PARTICIPATIVO
}

\author{
THE TOURIST SYSTEM OF COPAL'S COMMUNITY, \\ NICOYA, GUANACASTE, COSTA RICA. A \\ PARTICIPATIVE APPROACH
}

\author{
Marlene Lizette Flores-Abogabir ${ }^{1}$ \\ Meylin Alvarado-Sánchez ${ }^{2}$ \\ Universidad Nacional de Costa Rica, Costa Rica.
}

\section{RESUMEN}

El propósito de este trabajo fue realizar un diagnóstico de las potencialidades turísticas de la comunidad de copal, siguiendo el enfoque del sistema turístico en espacios rurales; detallando cada uno de los elementos que influyen en la calidad de la actividad turística local, tales como: los recursos, el capital social comunitario, el diseño de la oferta de productos y/o servicios, el marco legal e institucional, además de los factores económicos, ambientales, políticos y de financiamiento alternativo para la implementación de una propuesta de turismo rural, entre otros. En la identificación de los elementos de este sistema, se aplica una serie de instrumentos de inventario y valoración de la vocación turística, así como visitas de campo, talleres comunales y técnicas cartográficas, de manera participativa con miembros de las organizaciones locales de base. Los resultados de esta investigación muestran que los recursos y atractivos de esta comunidad son diversos, donde predominan los de tipo natural, playas, manglares, esteros, salinas y el Golfo de Nicoya; además de montañas,

1 Licenciada en Economía y M.Sc. en Desarrollo Rural, Académica de la Vicerrectoría de Investigación y Extensionista de la Escuela de Geografía de la UNA. Correo electrónico marlene.flores.abogabir@una.cr.

2 Geógrafa, Licenciada en Educación Ambiental y Máster en Desarrollo Comunitario, Académica Extensionista de la Escuela de Geografía de la UNA. Correo electrónico meylin.alvarado.sanchez@una.cr.

Fecha de recepción: 15 de agosto de 2016

Fecha de aceptación: 02 de noviembre de 2016 
Marlene Lizette Flores-Abogabir, Meylin Alvarado-Sánchez. The tourist system of copal's community, Nicoya, Guanacaste, Costa Rica. A participative approach

miradores, ríos y cataratas. Existen también atractivos culturales y arquitectónicos como las comidas típicas, fiestas patronales, ferias culturales, cementerio indígena y casa antigua; por otro lado, existe una fortaleza en el capital social de las organizaciones comunitarias, líderes comunales, así como pequeños empresarios operando de manera informal y potenciales microempresarios.

Palabras clave: Sistema turístico, diagnóstico participativo, inventario turístico, oferta turística y demanda turística.

\begin{abstract}
The purpose of this research was to diagnose the touristic potential of the community of Copal by implementing the tourist system focused on rural spaces. Each one of the elements that influences the quality of the local tourist activities were detailed in order to propose the implementation of a rural tourism alternative which includes: resources, social community capital, design of the products and/or services offered, legal and institutional framework, as well as economic, environmental, political, and alternative financial factors. The elements of the system were identified with the participation of the local-based organizations and included the application of a series of inventory and valuation instruments of tourism vocation, which included fieldwork, community workshops, and cartographical techniques. The results of this research show that the resources and attractions of this community are diverse and the natural ones such as beaches, mangroves, estuaries, salt lakes, mountains, lookout points, rivers, waterfalls, and the Nicoya Gulf prevail. There are also cultural and architectural attractions such as traditional foods, patron saint festivals, cultural fairs, indigenous cemeteries, and antique homes. On the other hand, the social capital represented by community organizations and leaders, as well as small entrepreneurs operating within the informal sector, represent an important strength within the community.
\end{abstract}

Keywords: Tourism system, participatory diagnosis, tourist inventory, tourist offer and tourist demand.

\title{
Introducción
}

El Turismo Rural Comunitario (TRC) es una alternativa de desarrollo para las comunidades rurales, como una actividad complementaria que dinamice sus actividades tradicionales, como la pesca, agricultura y ganadería. Para esto, es necesaria la identificación del potencial turístico de las comunidades, mediante un diagnóstico del sistema turístico. La presente investigación muestra el diagnóstico de este en la comunidad de Copal de Nicoya, en Guanacaste, Costa Rica, que permitió inventariar sus recursos turísticos; y la valoración de su vocación turística, como un aporte al fortalecimiento de la actividad turística de la comunidad.

\section{Objetivo}

Realizar un diagnóstico de las potencialidades históricas, naturales, culturales y ambientales de la Comunidad de Copal, para caracterizar las fortalezas, oportunidad, debilidades y amenazas en el desarrollo de la actividad turística. 
Marlene Lizette Flores-Abogabir, Meylin Alvarado-Sánchez. El sistema turístico de la comunidad de Copal, Nicoya, Guanacaste, Costa Rica. Un diagnóstico participativo

\section{Conceptos básicos}

Los conceptos básicos relacionados con la presente investigación son: turismo rural, turismo rural comunitario y sistema turístico.

Turismo Rural y Turismo Rural Comunitario

Alvarado (2007), citando a la OMT (1995), menciona que el concepto de turismo se refiere a "las actividades que realizan las personas durante sus viajes y estancias en lugares distintos al de su entorno habitual, por un período de tiempo consecutivo menor a un año, con fines de ocio, por negocios y otros motivos ". Para Sancho (1998), ésta es una definición amplia y flexible que caracteriza las principales actividades del turismo, que son:

- Introducción de los posibles elementos motivadores del viaje, "ocio, negocios, otros".

- Acotación temporal del período menor a un año, un período realmente amplio.

- Delimitación de la actividad desarrollada antes y durante el período de la estancia.

- Localización de la actividad turística, como la realizada fuera del entorno habitual de la persona, que consiste en una cierta área alrededor de su lugar de residencia, más todos aquellos lugares que visita frecuentemente.

Por otra parte, Alvarado (Íbid., citando a Quesada, 2000), indica que el turismo no solamente contempla el viaje del turista sino también todo el complejo proceso de organización, promoción y prestación de servicios demandados, tanto en el origen como en el destino, lo que implica diversidad de relaciones e impactos. Es por eso que Sancho (op. cit.), dice que "la naturaleza de la actividad turística es un resultado complejo de interrelaciones entre diferentes factores que hay que considerar conjuntamente desde una óptica sistemática, es decir, un conjunto de elementos interrelacionados entre sí, que evolucionan dinámicamente."

Dentro de este marco, Morera (2006), sostiene que el Turismo Rural, como concepto, no presenta una definición única, sino que su caracterización es bastante amplia; sin embargo, la mayoría de investigadores de los países europeos lo definen como aquellas actividades compuestas por una 
oferta integrada de ocio y recreación dirigida a una demanda cuya motivación principal es el contacto con el entorno autóctono y que potencia la interrelación con la sociedad local.

De esta forma, Alvarado (2007), citando Morera (Ibid), indica que este tipo de turismo se refiere a todas aquellas actividades turísticas que se realizan en espacios rurales, donde se contempla el contacto con la comunidad local, sus actividades productivas y culturales. Éste cuenta con características propias que lo diferencian de otros tipos de turismo como: una oferta integrada basada en los recursos autóctonos, ya sean naturales como culturales y actividades productivas locales. Además, la oferta está en manos de los pobladores locales y se desarrolla en pequeña escala, se ofrece a través de pequeñas y medianas empresas, de tipo familiar o cooperativas comunales.

Cuando el Turismo Rural está en manos de organizaciones comunales, se convierte en Turismo Rural Comunitario; éste implica una participación activa de la población local, mediante grupos organizados, que al mismo tiempo, desempeñan acciones de protección y educación ambiental, para la preservación de recursos naturales y culturales. Este tipo de turismo surge en Costa Rica, a inicios de los años 90, a través de los grupos de base asociativa, como organizaciones conservacionistas, asentamientos campesinos, grupos organizado de mujeres y territorios indígenas, en su mayoría financiados parcialmente por la cooperación internacional (ACTUAR, 2004, citado por Alvarado, 2007).

\section{El sistema turístico}

En Geografía del Turismo se propone el estudio de la actividad turística como un sistema por medio del cual se visualicen los diversos elementos que permiten el desarrollo de la misma, y se hace un análisis con una óptica integral. En este sentido, Sancho (Op cit), señala que la actividad turística es compleja y dinámica; en ella intervienen, interactúan y evolucionan diferentes elementos, que es necesario visualizar desde una óptica sistemática; en este contexto se distingue los siguientes elementos básicos:

- $\quad$ Los turistas: Éstos son la demanda, los que eligen el destino que visitarán. 
- $\quad$ El espacio geográfico: Es el espacio físico en el que se ubican los recursos turísticos, y donde interactúan la oferta, la demanda turística y la población local.

- La oferta: Son los bienes y servicios turísticos que hacen posible que los recursos turísticos puedan ser consumidos y comercializados.

- Los operarios o agentes que promocionan y comercializan los recursos turísticos: Morera (Op cit), les llama agentes públicos y privados que promocionan y comercializan los recursos turísticos, y los convierten en productos de acuerdo a las necesidades de la demanda.

- $\quad$ Los sistemas de transportes, conectividad y movilidad: Éstos tienen como finalidad organizar los viajes de los turistas entre los espacios emisores y los receptivos.

De acuerdo con Barrera (2003, citado por Alvarado, 2007), el producto turístico, es "el conjunto de componentes que satisfacen una experiencia de viaje que responde a las expectativas de un segmento del mercado". Por otra parte, el recurso turístico se refiere a la base sobre la que se asienta la actividad turística.

Morera (Op cit), señala que un factor fundamental a considerar dentro de la gestión turística son los recursos y atractivos turísticos, especialmente dentro del segmento de interés, por lo cual su evaluación, que implica tanto el inventario como su valoración, determina la potenciación del turismo en los espacios rurales. La evaluación debe valorar los recursos utilizados y los potenciales, e identificar la situación actual de la infraestructura, las vías de comunicación y otras facilidades requeridas en la actividad turística.

\section{Copal. Generalidades geográficas Antecedentes}

De acuerdo con Flores (2009), el territorio de la comunidad de Copal, ofrece durante todo el año una serie de recursos que pueden contribuir al ingreso económico de los pobladores de la comunidad, por medio de un producto turístico que dinamice las actividades tradicionales y ofrezca al turista una "experiencia de viaje". La pesca y ganadería son las actividades económicas más importantes de la comunidad, representan el $71,7 \%$ del total de actividades de la comunidad, sin embargo, del total de 
hogares únicamente representan el 33,6\%, dejando al resto en condición de subempleo (empleos ocasionales como peones agrícolas, jornaleros, en camaroneras), lo que genera un desplazamiento a otros lugares del país en busca de empleo. Así la actividad turística se convierte en una alternativa productiva para la economía local. En ese sentido, el TRC en la comunidad de Copal puede ayudar a complementar la economía tanto comunitaria como familiar y potenciar de alguna manera, el desarrollo de actividades económicas como la agricultura, la pesca, la artesanía, y otros servicios.

Por lo anterior, los recursos naturales, socioculturales e históricos presentes en la comunidad de Copal, se consideran una potencialidad para el éxito de una propuesta de TRC; en la medida en que se conviertan en un atractivo turístico para la oferta local. Por otro lado, el factor organizacional en la comunidad de Copal es considerado como una potencialidad para el desarrollo del TRC, en este contexto destaca la Asociación de Desarrollo con sus comités de trabajo (Escuela, Iglesia, Salud y Deporte) y su Junta de Educación; la Asociación de Mujeres Contra la Violencia y por el Desarrollo y la Paz Social de Copal, con sus actividades para el turismo rural; el BANCOMUNAL con asistencia financiera a sus pobladores; las Asociaciones Administradoras del Acueducto (ASADA), como responsables de proveer agua potable y velar por el manejo ambiental del lugar, así como el trabajo comunal de las familias del lugar.

\section{Ubicación Geográfica}

Copal, es una pequeña comunidad rural que se ubica en la costa noroeste del Golfo de Nicoya, específicamente en el distrito cuarto de Quebrada Honda, Cantón de Nicoya, provincia de Guanacaste, aproximadamente a 28 kilómetros de la Ciudad de Nicoya. 
Marlene Lizette Flores-Abogabir, Meylin Alvarado-Sánchez. El sistema turístico de la comunidad de Copal, Nicoya, Guanacaste, Costa Rica. Un diagnóstico participativo

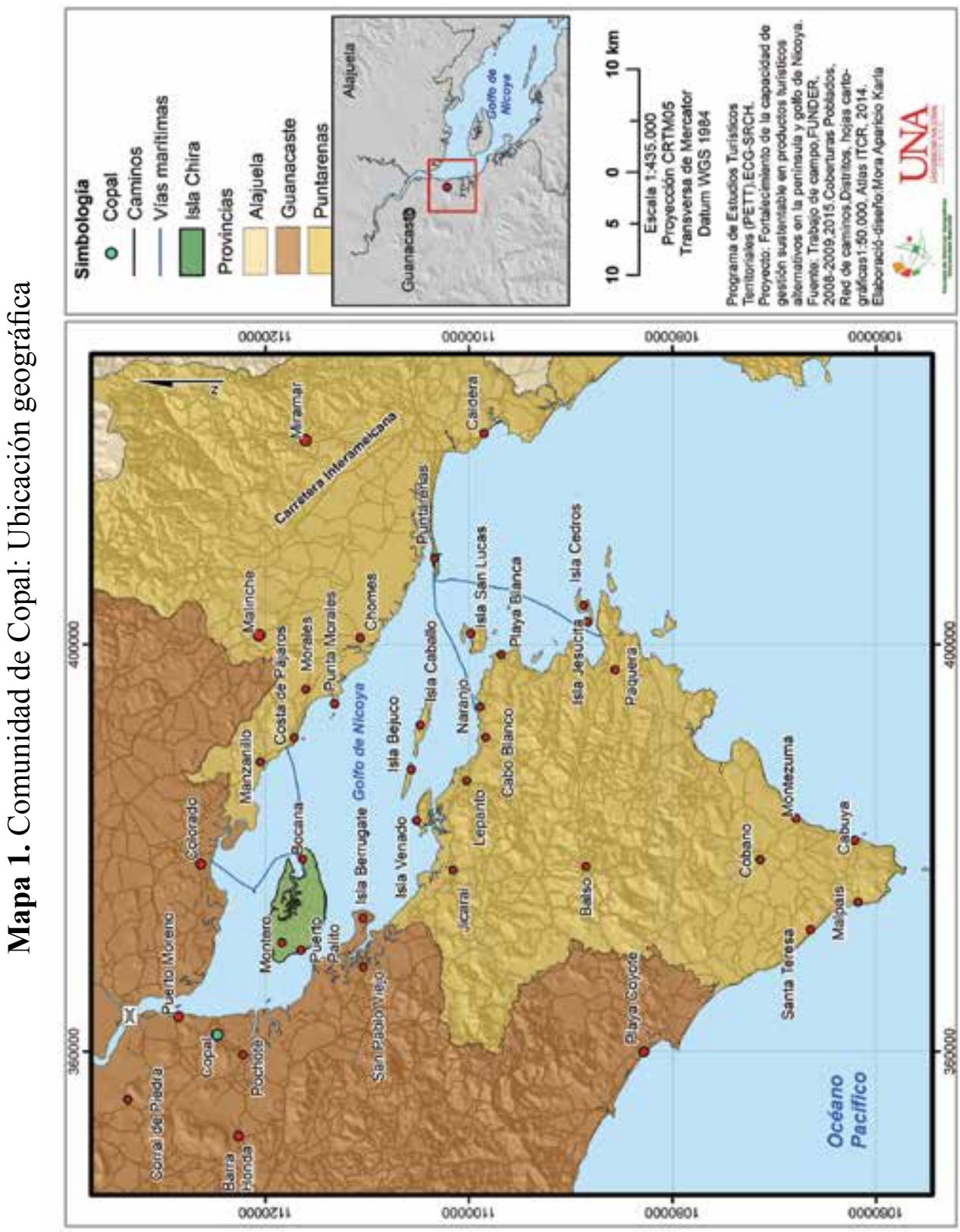

Revista Geográfica de América Central No Especial ISSN 1011-484X, I Semestre 2017, pp. 209-242 215 


\section{Distribución de la población}

En el censo poblacional, realizado por Flores (2009), se identificó que la comunidad cuenta una población total de 873 habitantes $(51,43 \%$ son hombres y el $48,57 \%$ son mujeres); el $72,16 \%$ son personas mayores de 15 años. Además este estudio identificó que esta comunidad posee 211 viviendas que representan los hogares, con una proyección de 50 viviendas más que están en construcción en el sector de Villa Bonita, bajo el Programa de Bono de la Vivienda y Lote.

\section{METODOLOGÍA}

La metodología que guío este trabajo se fundamente por Alvarado, Flores \& Padilla (2008), y comprende las siguientes etapas:

Para el diagnóstico del sistema turístico

- Búsqueda de información de fuentes secundarias y primarias para recolección de información para el diagnóstico.

- Revisión bibliográfica, visitas de campo, aplicación de instrumentos, sistematización de la información recolectada.

- Entrevistas abiertas a la oferta turística, encuestas a la demanda turística.

Para el potencial turístico de la comunidad

- Realizar un inventario de los recursos turísticos que permita identificar el potencial turístico de las comunidades involucradas.

- Inventario turístico, técnicas estadísticas, giras de campo, Sistemas de Información Geográfica.

- $\quad$ Aplicación de fichas técnicas, fichas de evaluación de los recursos y atractivos turísticos, Sistema de Posicionamiento Global.

\section{ANALISIS DEL SISTEMA TURISTICO DE LA COMUNIDAD DE COPAL}

\section{Inventario de los recursos turíticos}

Los recursos y atractivos turísticos de la comunidad de Copal se identificaron y ubicaron con líderes de las comunidades, mediante la técnica del mapeo participativo, en el que se utilizaron diversas herramientas como hojas topográficas 1:50000 del Instituto Geográfico Nacional

216 Revista Geográfica de América Central No Especial ISSN 1011-484X, I Semestre 2017, pp. 209-242 
(IGN) de Talolinga y Matambú; el Segmento Censal a diversas escalas del Instituto de Estadísticas y Censos (INEC), correspondiente al distrito de Quebrada Honda._En este mapeo se hizo el levantamiento, validación y georreferenciación de los recursos mediante Sistemas de Posicionamiento Global (GPS), Sistemas de Información Geográfica (SIG) y la aplicación de seis fichas de inventario de recursos y/o atractivos turísticos.

Los recursos y atractivos turísticos identificados se listan en el siguiente cuadro, de acuerdo con la clasificación establecida por la OEA y listada por Alvarado (2007) de la siguiente manera: sitios naturales, museos y manifestaciones culturales, realizaciones técnicas, científicas y contemporáneas, y acontecimientos programados. El mapa 2 muestra la ubicación de cada uno de éstos. 


\section{CUADRO 1. COMUNIDAD DE COPAL: RECURSOS Y ATRACTIVOS IDENTIFICADOS}

\begin{tabular}{|c|c|c|}
\hline Categoría & Tipo & Subtipo (Atractivo) \\
\hline $\begin{array}{l}\text { 1. Sitios } \\
\text { Naturales }\end{array}$ & 1.2. Montaña & $\begin{array}{l}\text { El Golfo de Nicoya } \\
\text { Manglar y Estero Letras } \\
\text { Río Tempisque } \\
\text { Nacientes de agua y cataratas } \\
\text { Playa Conchita } \\
\text { Cerros y miradores de Copal: las Pozas, } \\
\text { la Palma, la Tigra, Sombrero, Carazo y } \\
\text { Pochote }\end{array}$ \\
\hline $\begin{array}{l}\text { 2. Museos y } \\
\text { manifestaciones } \\
\text { culturales }\end{array}$ & $\begin{array}{l}\text { 2.1. Comidas y bebidas } \\
\text { típicas } \\
\text { 2.2. Música y danza } \\
\text { 2.3. Manifestaciones y } \\
\text { creencias populares }\end{array}$ & $\begin{array}{l}\text { Comidas típicas: Comidas a base de } \\
\text { mariscos y de maíz } \\
\text { Música de marimba } \\
\text { Bailes típicos } \\
\text { La Comunidad de Copal } \\
\text { Leyendas } \\
\text { Paseos en carretas } \\
\text { Celebraciones religiosas } \\
\text { Casa Antigua } \\
\text { Puerto Histórico } \\
\text { Ruinas Felo } \\
\text { Piedra Cabeza de Dinosaurio } \\
\text { Zona Arqueológica y Cementerio } \\
\text { Indígena }\end{array}$ \\
\hline $\begin{array}{l}\text { 3. Realizaciones } \\
\text { técnicas, } \\
\text { científicas y } \\
\text { contemporáneas }\end{array}$ & $\begin{array}{l}\text { 3.1. Explotación del recurso } \\
\text { marino y agropecuario }\end{array}$ & $\begin{array}{l}\text { Pesca artesanal } \\
\text { Cultivo de camarón } \\
\text { Salinas } \\
\text { Cultivos y plantaciones agrícolas } \\
\text { Lecherías artesanales }\end{array}$ \\
\hline $\begin{array}{l}4 . \\
\text { Acontecimientos } \\
\text { programados }\end{array}$ & 4.1 Eventos especiales & $\begin{array}{l}\text { Corridas de toros } \\
\text { Turnos } \\
\text { Ferias Patronales } \\
\text { Feria Cultural Copaleña }\end{array}$ \\
\hline
\end{tabular}

Fuente: Flores. (2009):68 
Marlene Lizette Flores-Abogabir, Meylin Alvarado-Sánchez. El sistema turístico de la comunidad de Copal, Nicoya, Guanacaste, Costa Rica. Un diagnóstico participativo

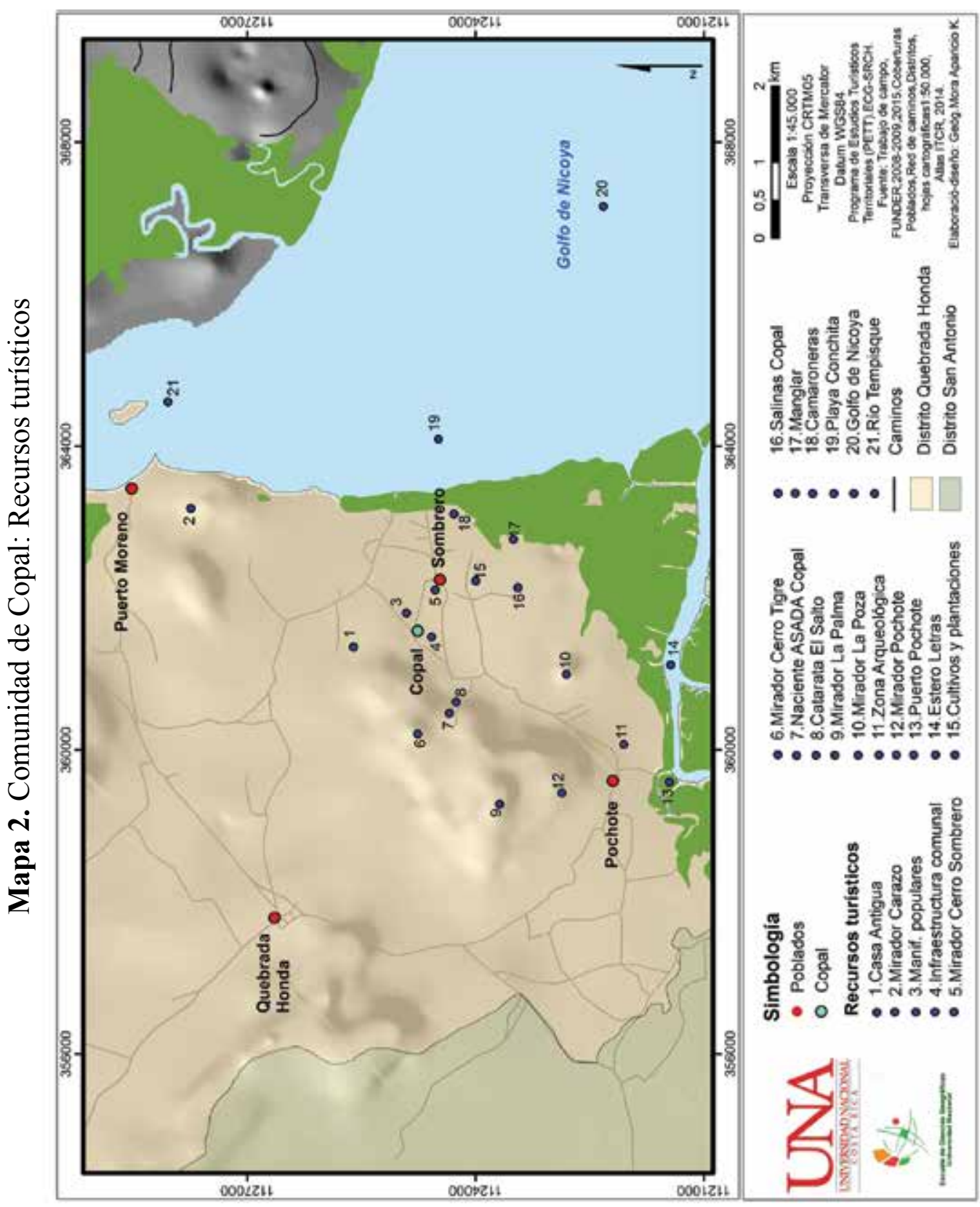

Revista Geográfica de América Central No Especial ISSN 1011-484X, I Semestre 2017, pp. 209-242 219 


\section{Descripción de los recursos turísticos}

Esta descripción se apega a las categorías mostradas en el cuadro 1. De acuerdo con Flores (2009), este punto se fortalece con la inclusión de fotografías de los diferentes recursos y atractivos, las cuales fueron tomadas en las giras y trabajos de campo realizadas el 2008, con apoyo de académicos y estudiantes de la Sede Regional Chorotega, la Escuela de Economía, y la Escuela de Ciencias Geográficas de la Universidad Nacional. Para la valoración de la vocación turística y los indicadores utilizados, referirse a los cuadros $2,3,4$ y 5 .

\section{1) Sitios naturales}

\section{Golfo de Nicoya}

Es el golfo más grande del país, ubicado en la costa pacífica de Costa Rica, y ofrece una diversidad de fauna y flora marino costera. Este recurso permite el desarrollo de pesca artesanal turística y tours dirigidos. Tiene una vocación turística media, porque aunque las actividades se realizan en panga, es necesario contar con chalecos salvavidas y motores reglamentados, así como facilidades requeridas para evitar accidentes. Por otro lado, para tener acceso al recurso la demanda de esfuerzo físico es mínima, el clima tiene una baja incidencia, lo que permite su disponibilidad tanto en periodo seco como en periodo lluvioso. 
Foto 1. Vista del Golfo de Nicoya desde Cerro la Tigra de Copal

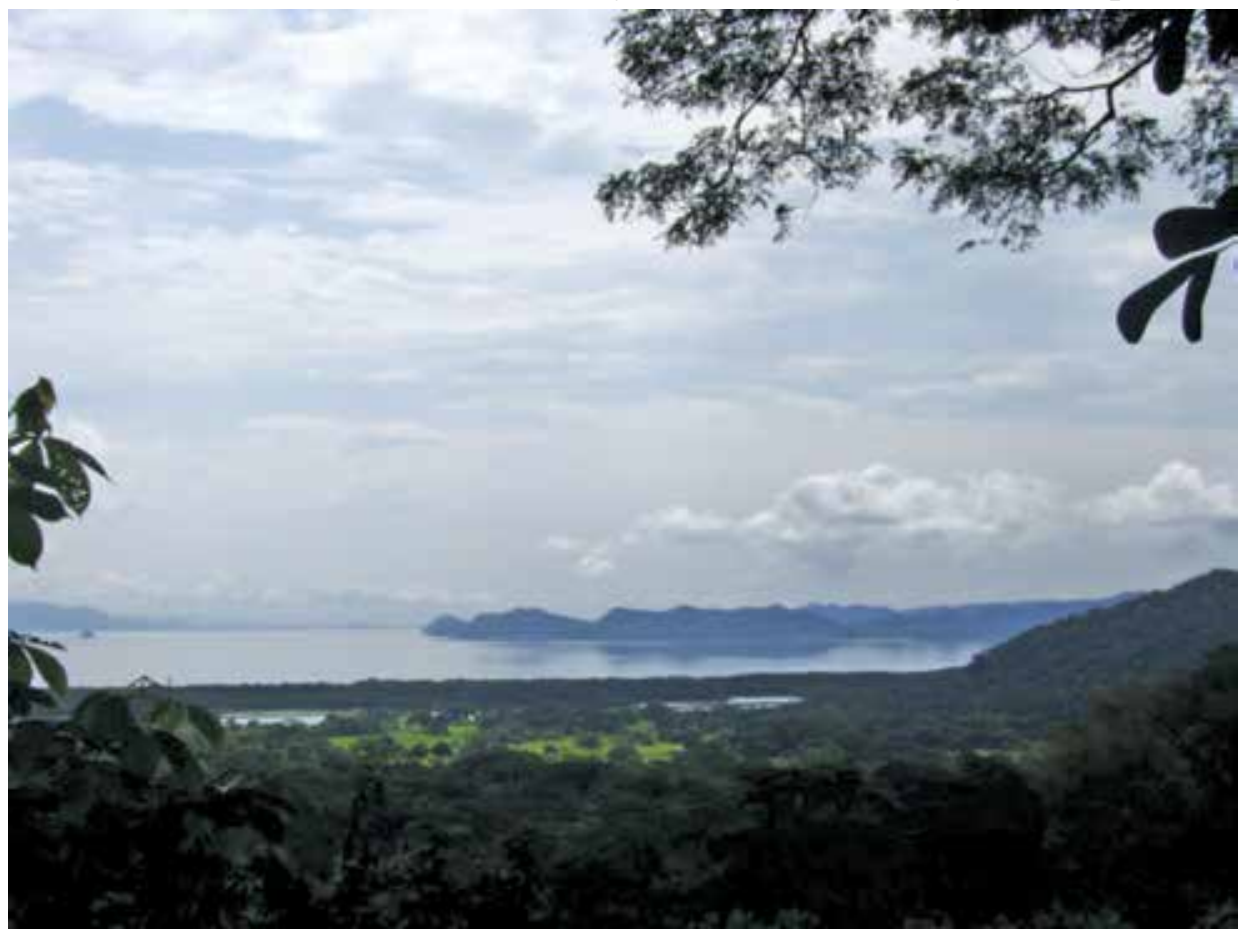

\section{Playa Conchita}

Es la única playa accesible en marea baja desde la comunidad; sólo es visitada en ocasiones por los mismos pobladores, es muy pequeña. No se oferta por la comunidad pero sí tiene potencial turístico. Tiene una vocación turística media, debido a que las condiciones climáticas tienen baja incidencia, requiere de un mínimo esfuerzo físico, y sólo se pueden realizar actividades concretas.

\section{Manglar y estero Letras}

Ubicados en la costa oeste del golfo de Nicoya, son pequeños bosques que tienen influencia de las mareas y albergan gran cantidad de especies terrestres y marítimas. Su oferta actual es incipiente; se brinda ocasionalmente servicio de tours dirigidos a grupos pequeños (uno a cinco turistas), por lo que se tiene en un potencial alto como atractivo turístico y una vocación turística media, porque las condiciones del clima tienen baja incidencia, 
requiere de un mínimo esfuerzo físico, su acceso se realiza por el embarcadero de Puerto Pochote, pero actualmente no existen las facilidades requeridas y reglamentadas para brindar el servicio de tours dirigidos.

Foto 2. Manglar y estero Letras

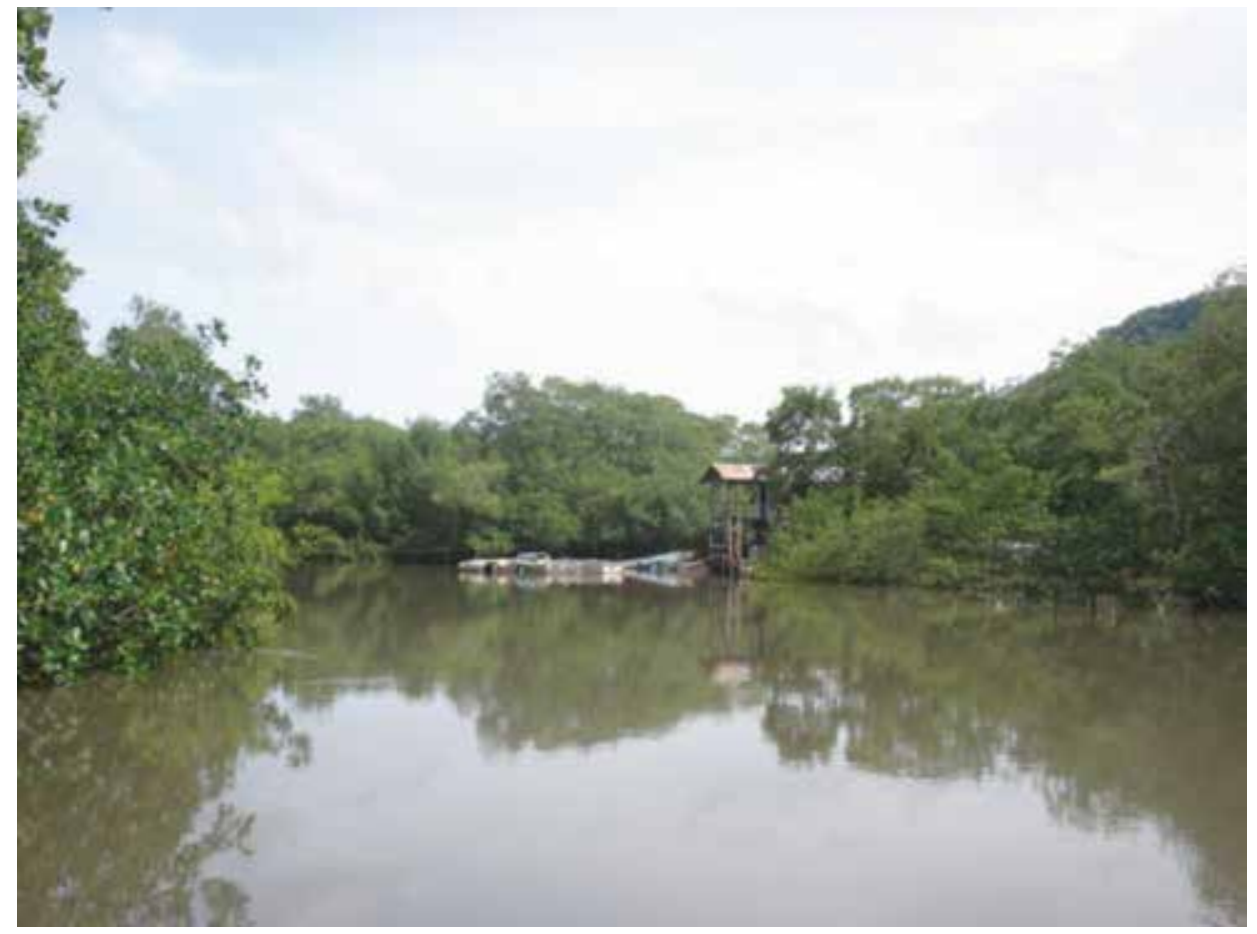

Río Tempisque

Es el río más largo del país, con una longitud de aproximadamente 130 Kilómetros, bordea la península de Nicoya y desemboca en el golfo de Nicoya; cuenta con diversos ecosistemas que permiten verlo como un recurso potencial desde la comunidad de Copal. Se pueden ofertar tours dirigidos en panga por el Río Tempisque, y hacer observación de fauna; así como bosque seco y el siempre húmedo; además permite la conectividad con otros lugares como Isla Pájaro y Palo Verde. Como recurso ofertado desde la comunidad, tiene una vocación turística media porque el recorrido se propone en panga lo que hace necesario contar con chalecos salvavidas y motores reglamentados. 
Marlene Lizette Flores-Abogabir, Meylin Alvarado-Sánchez. El sistema turístico de la comunidad de Copal, Nicoya, Guanacaste, Costa Rica. Un diagnóstico participativo

\section{Catarata El Salto}

Ubicada en el Cerro la Palma, es una caída de agua considerada por los pobladores como una piscina natural. Como recurso potencial, las actividades que se pueden realizar incluyen la observación de flora y fauna, camping y disfrute de la catarata y el río. Tiene una vocación turística media, al presentar una incidencia media en todos los indicadores que se utilizaron en la valoración.

Foto 3. Vista de la Catarata El Salto, Cerro La Palma de Copal

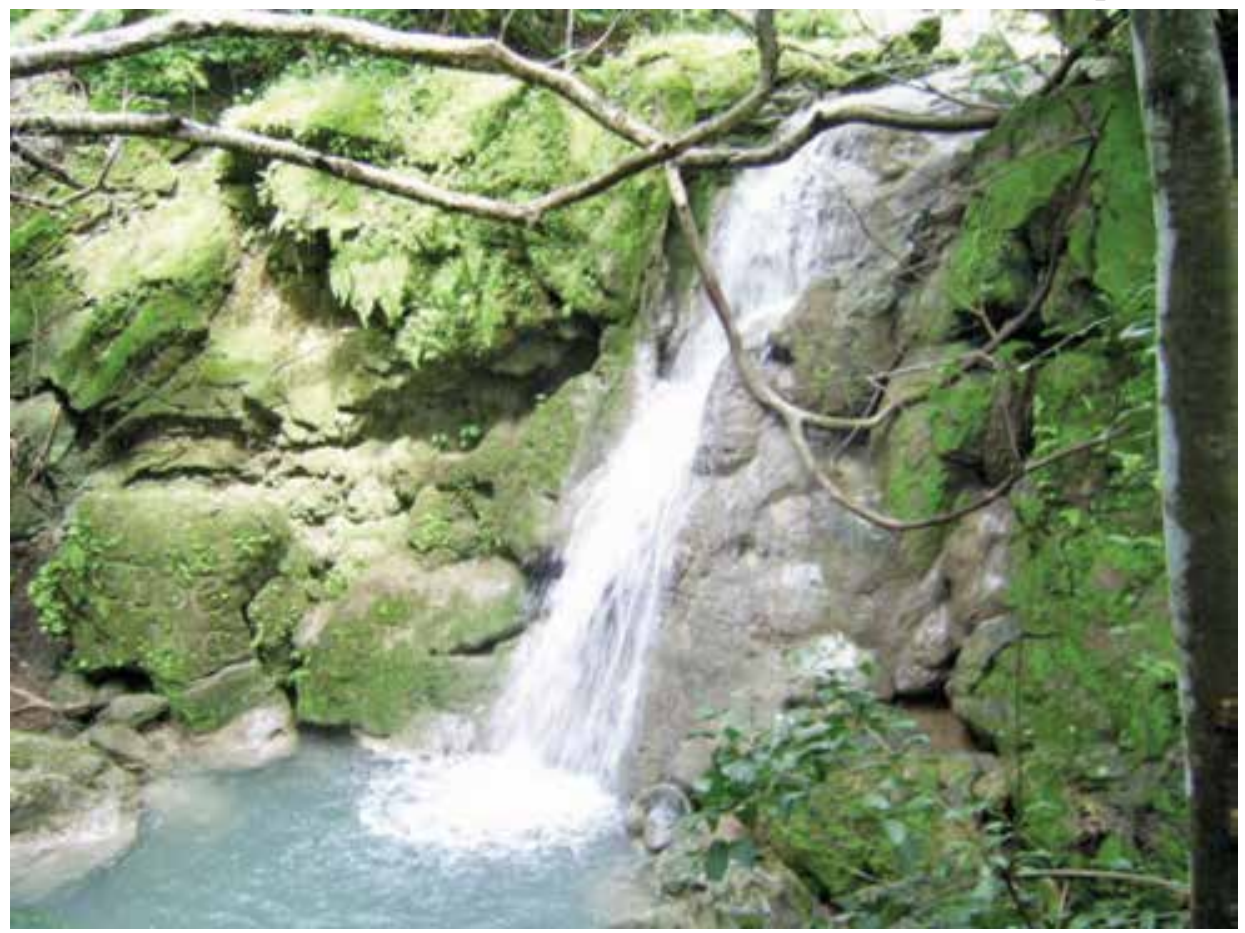

Cerros y miradores de Copal

Conocidos como Carazo, Sombrero, La Palma, La Tigra, Las Pozas y Pochote, son elevaciones de poca altitud (200 msnm). Cuentan con miradores y senderos naturales, distintas panorámicas, cavernas, entierros aborígenes y nacientes, entre otros atractivos. Como recurso potencial, presenta una vocación turística media en los indicadores utilizados. Esto se debe, en parte, a que el recurso turístico está relacionado con caminatas 
Marlene Lizette Flores-Abogabir, Meylin Alvarado-Sánchez. The tourist system of copal's community, Nicoya, Guanacaste, Costa Rica. A participative approach

dirigidas, por lo que las condiciones climáticas inciden de manera que su disponibilidad sería durante el período seco, que va de noviembre a mayo. Además, las actividades que se pueden realizar en el lugar presentan una diversidad media, y se limitan a caminatas y observación de flora y fauna.

Foto 4: Sendero natural Cerro La Tigra

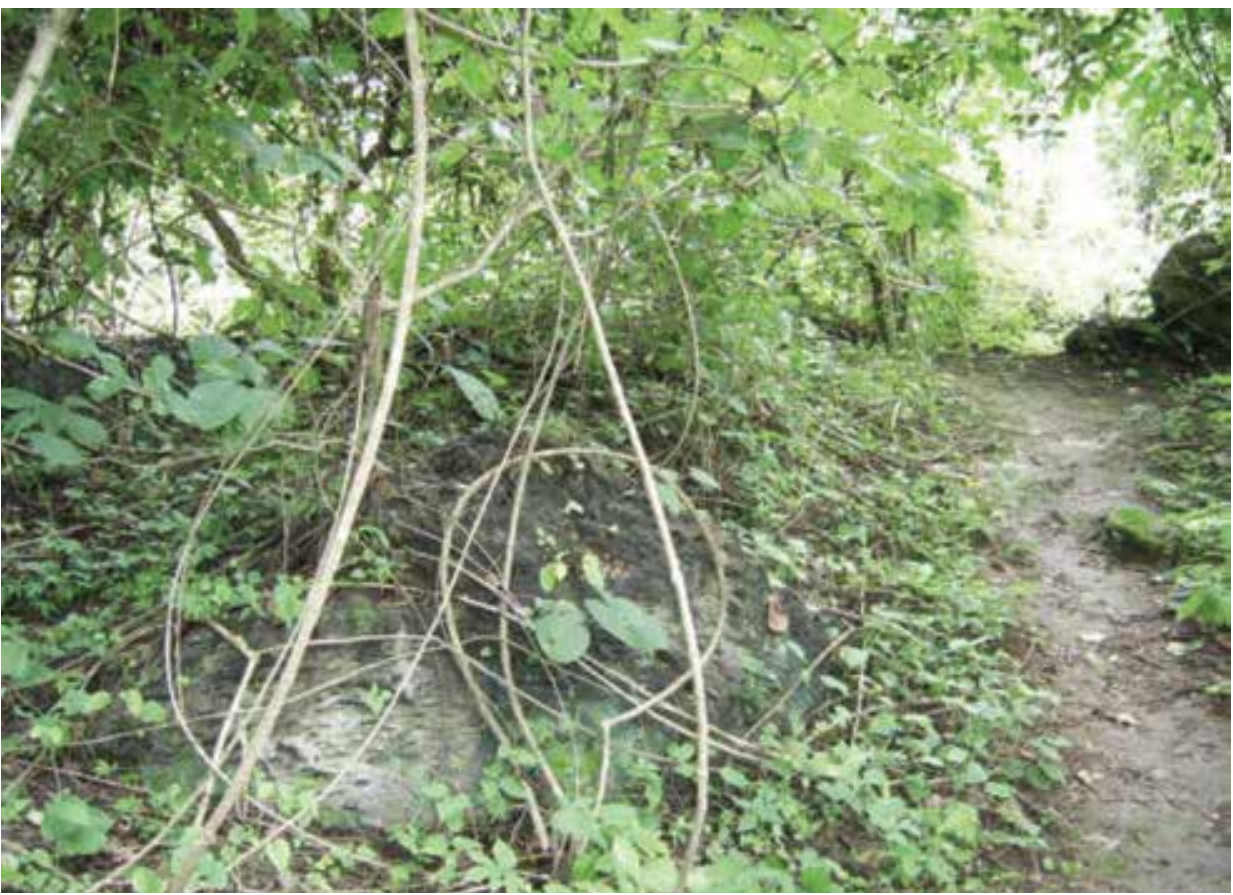

\section{2) Museos y manifestaciones culturales}

\section{La Comunidad de Copal}

Recibe su nombre por un árbol característico de la zona; es considerada como un recurso turístico porque tiene potencialidades que le permiten ofertar un TRC. Una de las particularidades que atrae a los turistas es el mismo nombre de la comunidad, además de tener facilidades de acceso, y poder desarrollar diversas actividades turísticas. Destacan dentro de sus atractivos, una casa antigua, cultivos y plantaciones, actividad ganadera, sus creencias populares, sus comidas a base de mariscos y maíz, su infraestructura taurina, además de los descritos particularmente. 
Marlene Lizette Flores-Abogabir, Meylin Alvarado-Sánchez. El sistema turístico de la comunidad de Copal, Nicoya, Guanacaste, Costa Rica. Un diagnóstico participativo

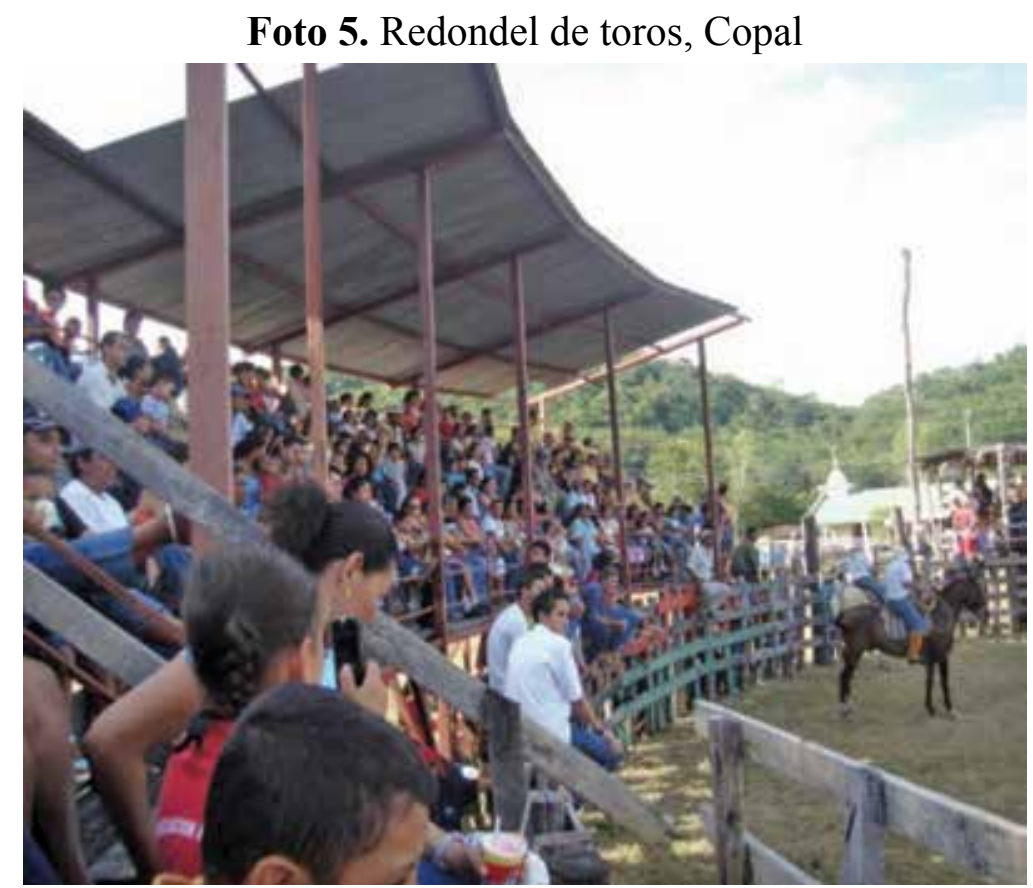

Tiene una vocación turística alta ya que, por sí misma, posee varias ventajas que hacen que sea un recurso con gran potencial para ser ofertado. El acceso a la comunidad de Copal no requiere de ningún esfuerzo físico, se puede llegar en vehículo particular o autobús; lo mismo sucede con los recorridos por la comunidad, debido a que la topografía sin pendiente y las cortas distancias hacen que no se deba incurrir en esfuerzos físicos demandantes. La comunidad de Copal es muy segura, cuenta con las facilidades requeridas para el disfrute de los visitantes y permite realizar diversas actividades como caminatas por la comunidad y por senderos, observación de flora y fauna, interacción con los habitantes y contacto con el modo de vida de la comunidad, entre otros. 


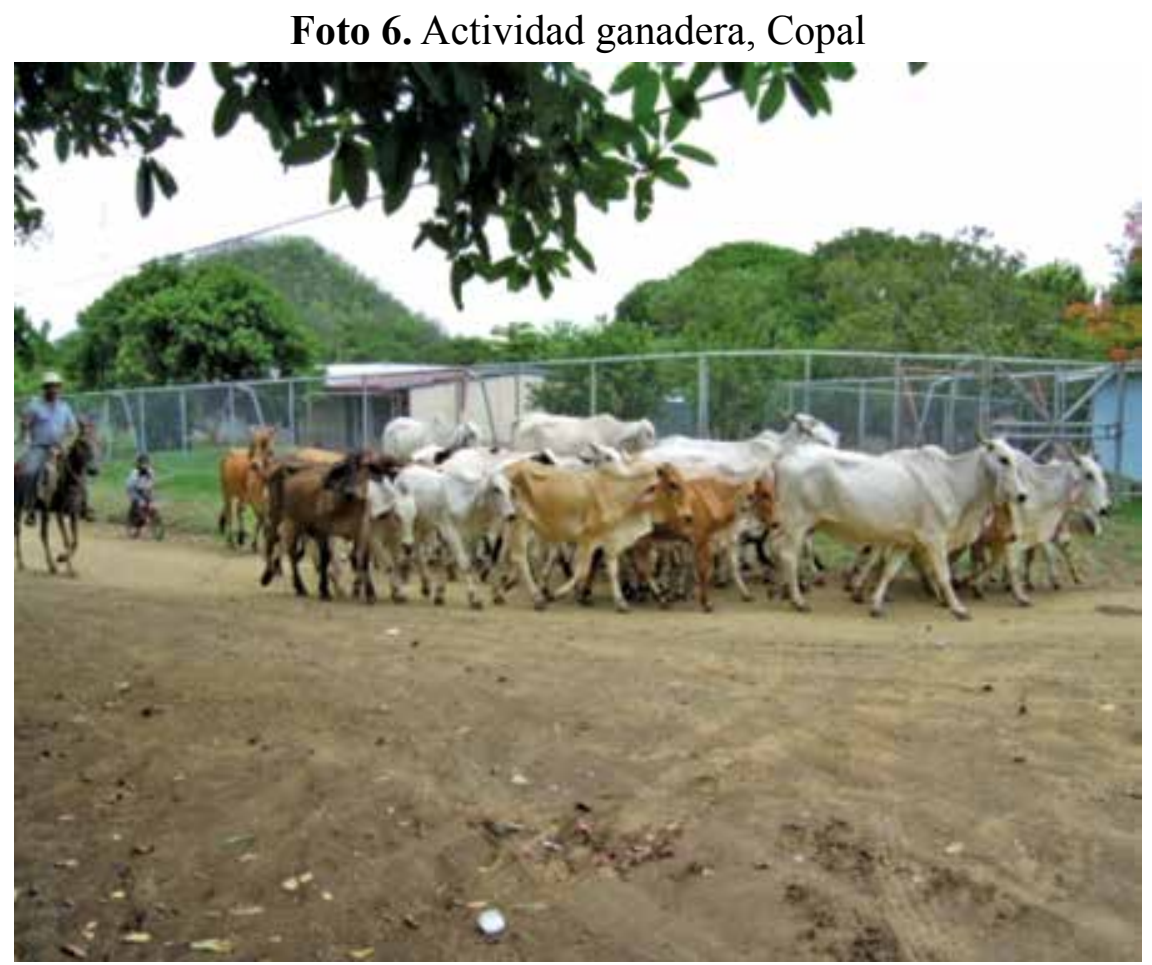

\section{Puerto Pochote}

Es un pequeño embarcadero ubicado a orillas del estero Letras, cuenta con una infraestructura para pequeñas embarcaciones (botes o pangas). Permite el acceso al estero, para la realización de actividades de caminatas y tours en panga dirigidos. Tiene una vocación turística media, ya que está disponible todo el año, hay facilidades de acceso y se requiere de mínimo esfuerzo para su visitación, no presenta riesgo para el visitante, tiene algunas facilidades requeridas, pero se realizan pocas actividades. 
Foto 7. Embarcadero Puerto Pochote, a orillas del Estero Letras

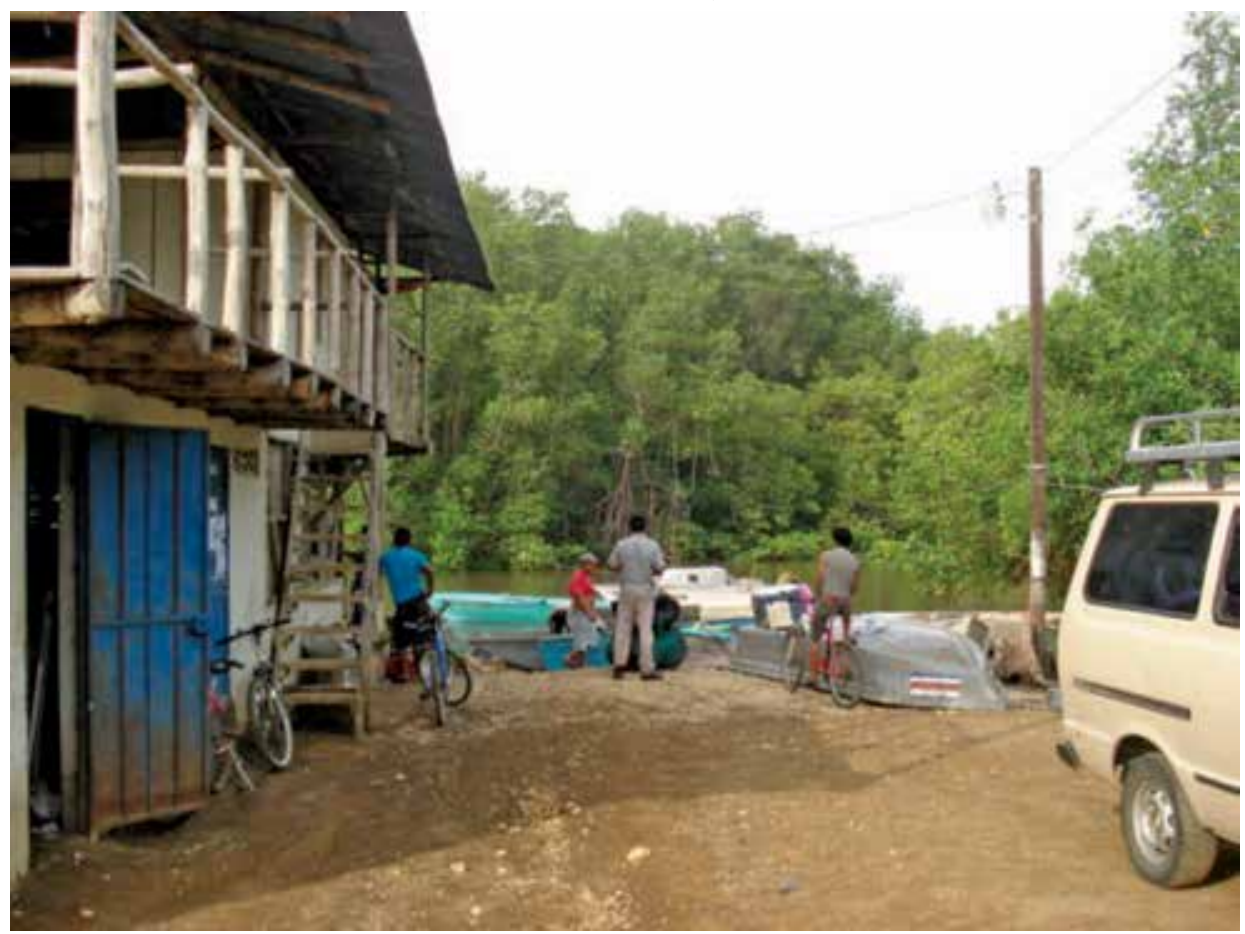

\section{Puerto Carazo}

Es uno de los primeros puerto de Guanacaste. Actualmente no funciona como embarcadero, aun presenta restos históricos del antiguo puerto. Como recurso se relaciona con caminatas dirigidas y la observación de flora y fauna. Posee una vocación turística media, la principal razón es que la seguridad tiene una alta incidencia en el recurso, porque no cuenta con las facilidades o recursos necesarios para evitar accidentes; Por otra parte, el tiempo atmosférico tiene una incidencia media, por lo que las condiciones climáticas pueden afectar su disponibilidad, ocasionando que este sólo sea utilizable durante el período seco, que se extiende de noviembre a mayo. Además, para llegar a este se debe realizar una caminata que supone un esfuerzo físico moderado. 
Marlene Lizette Flores-Abogabir, Meylin Alvarado-Sánchez. The tourist system of copal's community, Nicoya, Guanacaste, Costa Rica. A participative approach

Foto 8. Restos Históricos Puerto Carazo, Cerro las Pozas de Copal

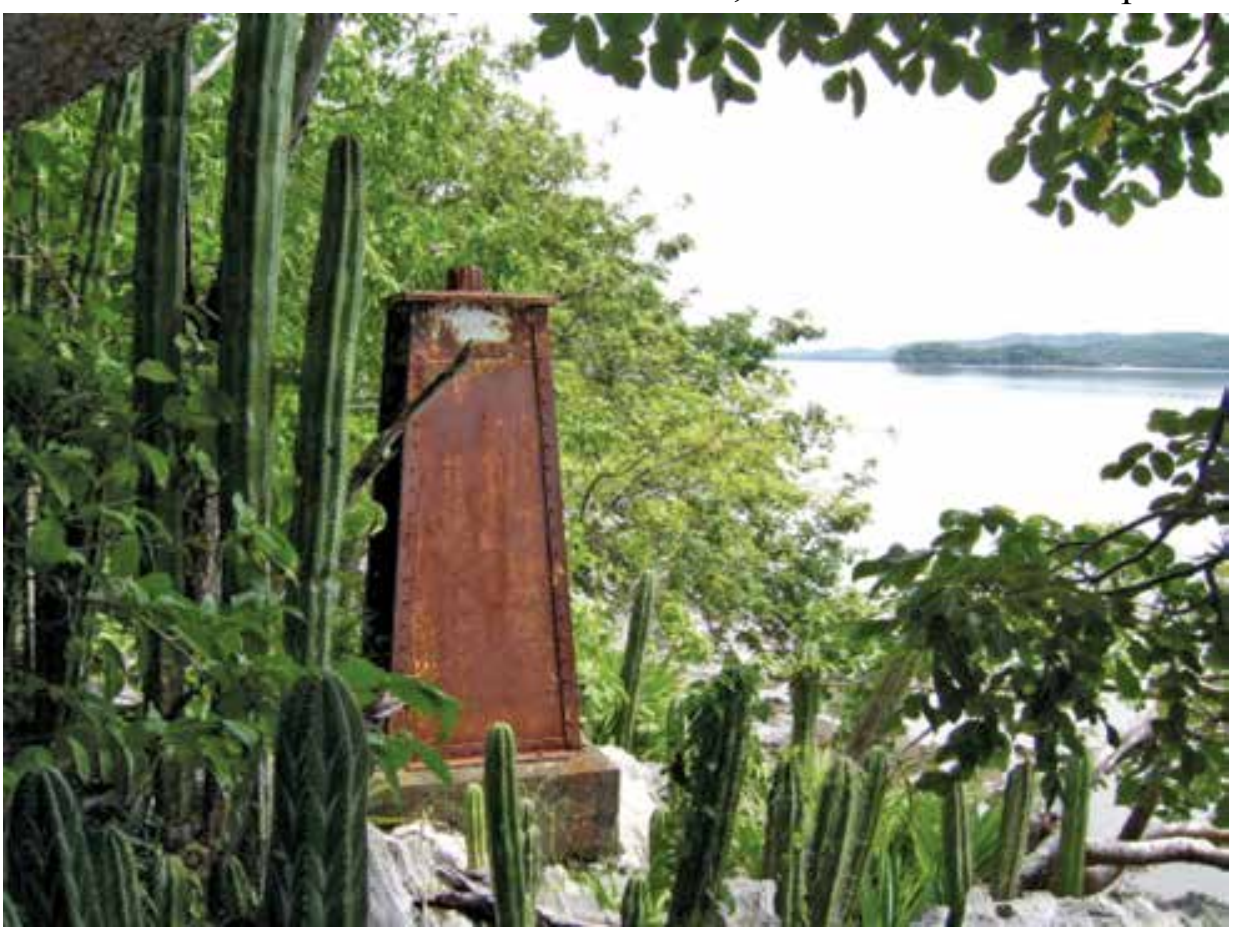

\section{Cementerio indigena}

Es un área cultural histórica; según el guía turístico local, José Raúl Villegas, se han descubierto vasijas de aproximadamente 2000 años de antigüedad, que son propiedad del Estado, y gestionadas y administradas por el Museo Nacional que ha realizado excavaciones. (Villegas, 2008). Actualmente, es un recurso potencial que se encuentra al natural, y que permitirá hacer caminatas dirigidas y complementarse con otros recursos. Tiene una vocación turística media, ya que está disponible todo el año, requiere de un esfuerzo físico mínimo, no presenta riesgo y las facilidades de acceso son buenas.

\section{Zona arqueológica}

Al igual que el cementerio indígena, la zona arqueológica denominada así por el Museo Nacional, presenta entierros indígenas que contienen parte de la historia de la región; actualmente es un recurso potencial 
Marlene Lizette Flores-Abogabir, Meylin Alvarado-Sánchez. El sistema turístico de la comunidad de Copal, Nicoya, Guanacaste, Costa Rica. Un diagnóstico participativo

con una vocación turística media, que permitirá hacer caminatas dirigidas y por encontrarse en el camino principal del sector de Pochote y estar disponible todo el año; sin embargo, hoy día se tiene prohibido el acceso.

Foto 9. Restos de vasijas encontradas en Copal

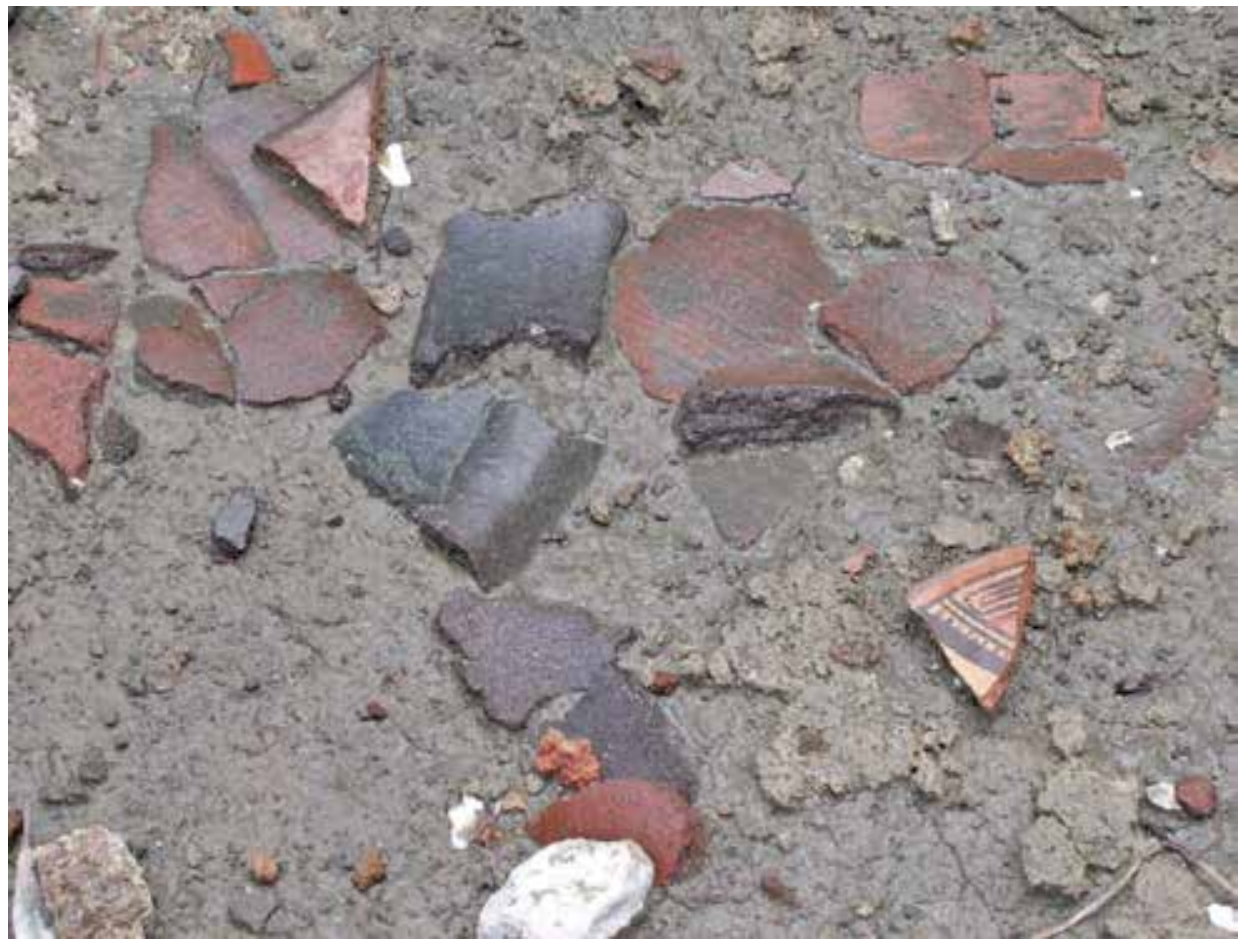


Foto 10. Sector Pochote

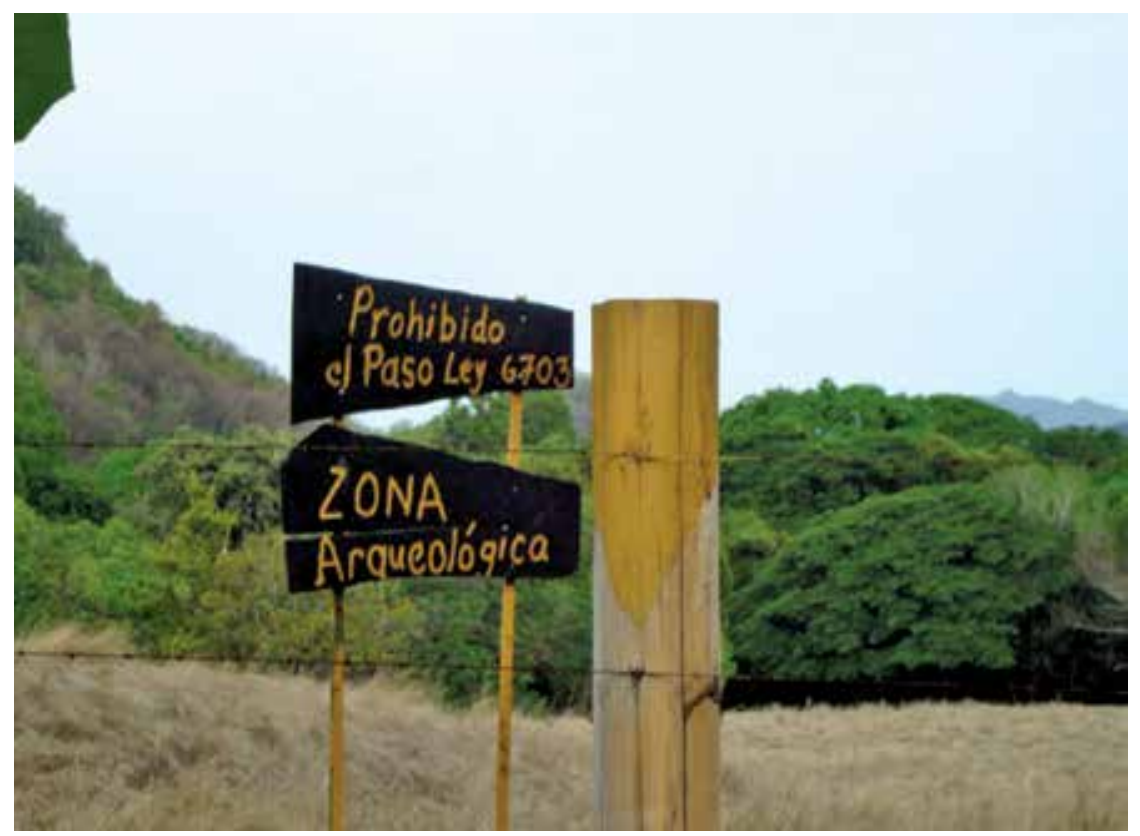

\section{3) Realizaciones técnicas, científicas y contemporáneas}

\section{Las salineras}

Fue considerada también una de las principales actividades económicas del golfo de Nicoya. En Copal las salineras están integradas principalmente por hombres, son microempresarios informales productores de sal para ganado a cargo de seis familias de la zona. Estas salineras generan solamente empleo familiar y prácticamente la mitad del año están cerradas. Tienen una vocación turística media, su oferta es incipiente y ofertada solamente por un guía turístico de la comunidad de Tortugero, lo que las convierte en un atractivo potencial y complementario con otros tours dirigidos. 
Marlene Lizette Flores-Abogabir, Meylin Alvarado-Sánchez. El sistema turístico de la comunidad de Copal, Nicoya, Guanacaste, Costa Rica. Un diagnóstico participativo

Foto 11. Sendero hacia las salineras de Copal

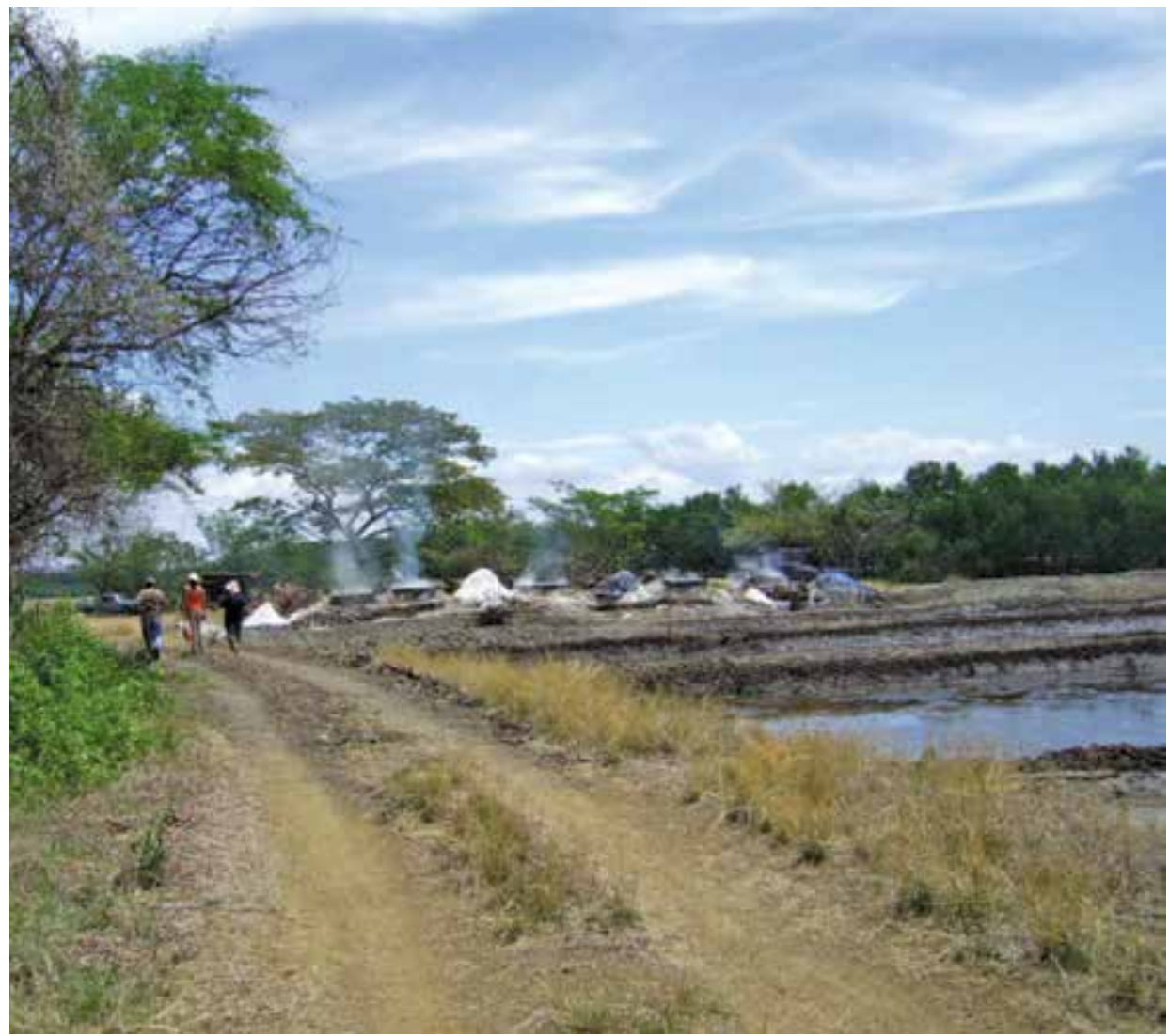

\section{Pesca artesanal}

Fue una de las principales actividades económicas del lugar. Según Narciso Reyes, (2009), actualmente esta actividad es realizada por el 90\% de las familias del sector de Pochote (27 familias) y según Guadalupe Padilla (2009) por 12 familias del resto de los sectores de Copal. Las técnicas artesanales las realizan en botes o pangas, trasmallo y con motor fuera de borda. Es realizada en el golfo de Nicoya, utilizando el puerto Pochote en estero Letras para su conexión. Para este no se ha realizado la valoración del potencial turístico; sin embargo, es un recurso en el cual se pueden involucrar los turistas. 
Marlene Lizette Flores-Abogabir, Meylin Alvarado-Sánchez. The tourist system of copal’s community, Nicoya, Guanacaste, Costa Rica. A participative approach

Foto 12. Grupo de pescadores en Puerto Pochote

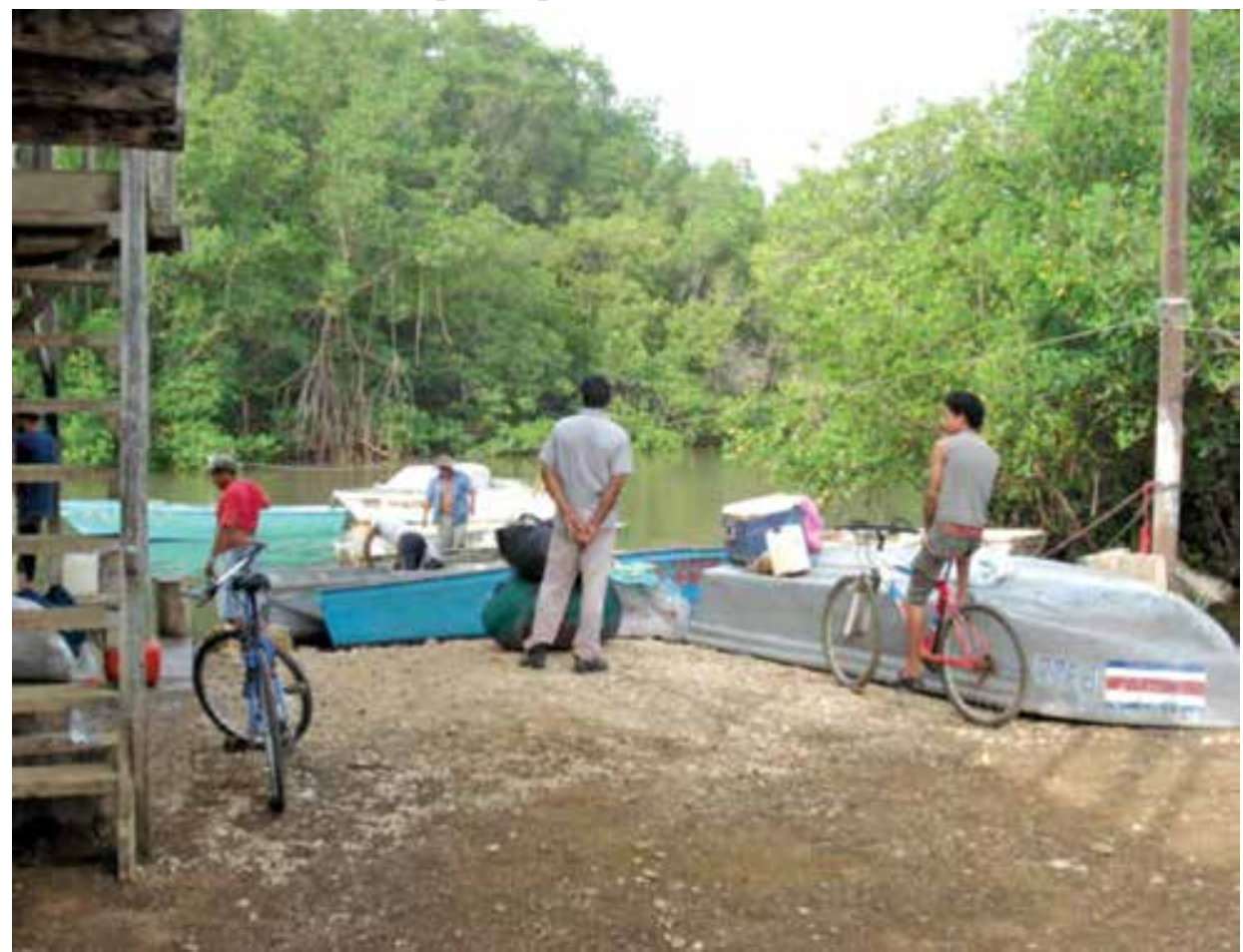

\section{Lecherías}

En la comunidad existen algunas familias que desarrollan la actividad ganadera de doble propósito; con ello de manera informal, las tradicionales lecherías pueden considerarse como un atractivo complementario para un producto turístico. Este atractivo aún no ha sido valorado; sin embargo, es un recurso potencial para la propuesta de TRC; actualmente además de pequeñas fincas ganaderas de la comunidad interesadas en introducir dicha actividad en sus fincas, hay dos proyectos emprendedores.

\section{4) Acontecimientos programados}

\section{Fiestas tradicionales del pueblo}

Se refieren específicamente a las fiestas tradicionales (patronales) del pueblo, celebradas del 4 al 9 de marzo de cada año. Tienen una vocación turística alta, ya que de la misma forma que la Feria Cultural, las 
fiestas patronales se realizan en el centro de la comunidad, por lo que el esfuerzo físico para su disfrute es mínimo; la misma ventaja se presenta con el acceso, debido a que éste tampoco implica un esfuerzo físico por parte de los turistas. Además, las fiestas patronales no presentan ningún riesgo para los visitantes; se cuenta con instalaciones en buen estado y se toman las precauciones debidas para evitar accidentes.

Foto 13. Visitantes internacionales en las fiestas tradicionales

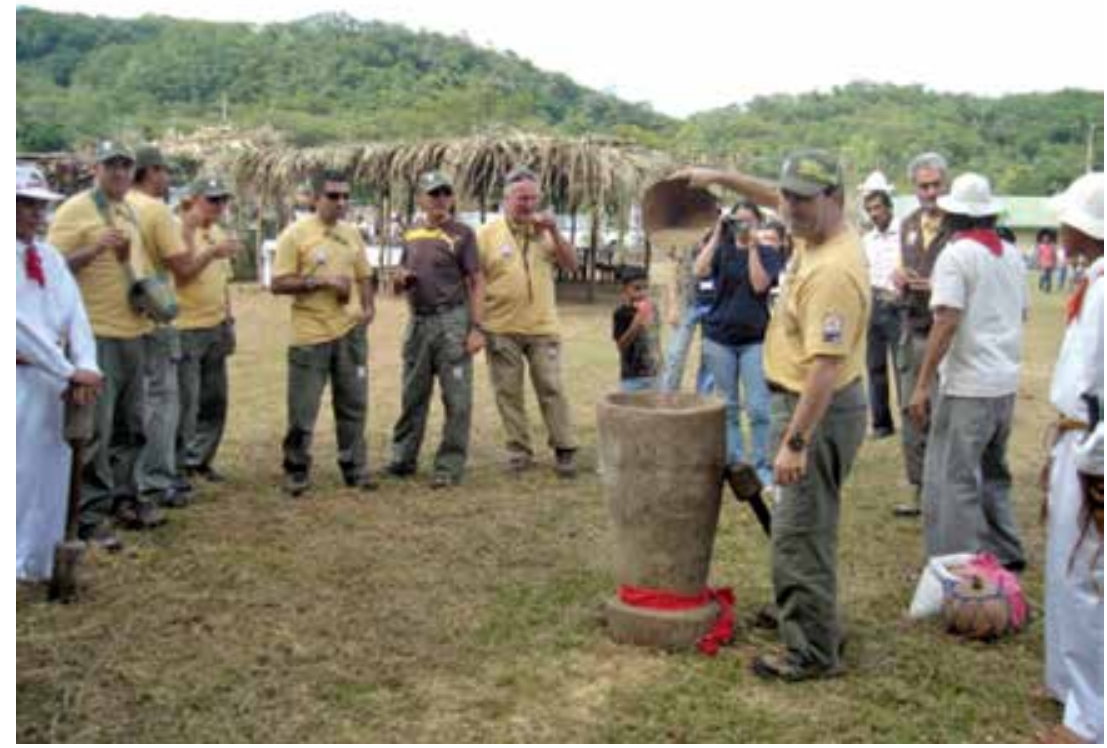

\section{Feria cultural copaleña}

Mezcla elementos de la cultura guanacasteca, tales como la gastronomía con un almuerzo típico, compuesto de varios platillos, donde los turistas pueden integrarse y participar en la preparación de los mismos; presentación de los montadores (toros) en el redondel de la comunidad (monta típica); música con marimba; presentación de bailes típicos guanacastecos en los que los visitantes pueden bailar con los integrantes del grupo de baile; interacción con la comunidad; entrega de recuerdos típicos de la artesanía guanacasteca, elaborados por habitantes de la comunidad o pueblos vecinos y despedida de los demandantes. Cada feria, como producto final, se desarrolla en un lapso de 3 horas y 15 minutos. 
Marlene Lizette Flores-Abogabir, Meylin Alvarado-Sánchez. The tourist system of copal's community, Nicoya, Guanacaste, Costa Rica. A participative approach

Foto 14. Actividades culturales, Copal

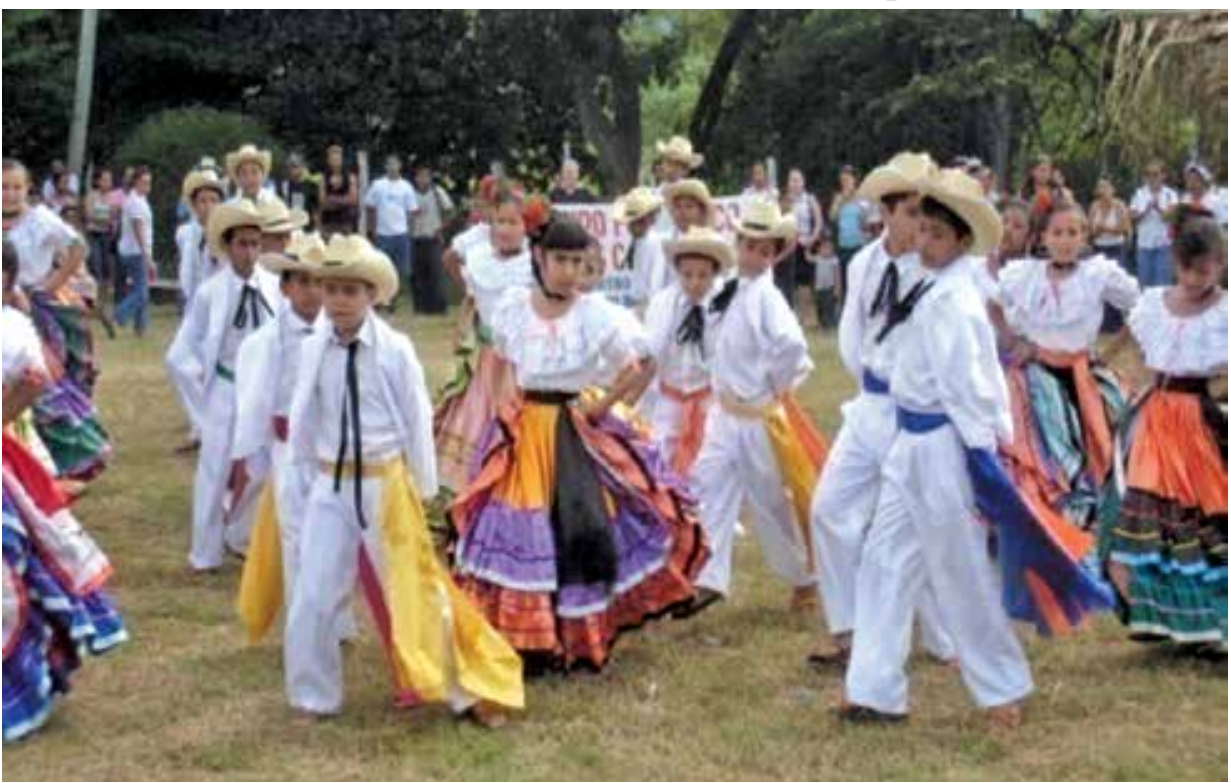

Es uno de los atractivos turísticos con mejor valoración; esto se debe, en parte, a que la feria es el principal producto turístico ofrecido por la comunidad de Copal. Presenta una vocación turística alta, a pesar de que sólo puede realizarse en período seco; sin embargo, la seguridad tiene una incidencia media, debido a que existen construcciones para desarrollar las diferentes actividades que son compartidas por diferentes organizaciones de la comunidad, el atractivo cuenta con algunas de las facilidades requeridas, pero el no contar con infraestructura propia, limita la realización de algunas actividades. No requiere de ningún esfuerzo físico por parte de los turistas, debido a que se realiza en el centro de la comunidad y no hay necesidad de desplazamiento; el acceso, debido a la topografía, y la ubicación del recurso no implican ninguna exigencia física y permiten que se realicen diferentes actividades en la infraestructura comunal.

\section{Valoración de la vocación turística}

De acuerdo con Alvarado (2007), una vez que se identifican y clasifican los recursos y atractivos según la metodología de la OEA, el paso que sigue es la evaluación; para lo cual existen dos metodologías: 
1. La jerarquización de los recursos y atractivos turísticos, se realiza mediante un examen crítico de los más relevantes, para establecer cinco jerarquías de mayor a menor importancia, en la que 5 es el tope superior.

2. El análisis de incidencia de factores que determinan la vocación turística de los mismos, planteada por Morera (2007) a través de la ficha de valoración de la vocación turística. En esta se define el grado de incidencia con una puntuación de 0 a 2 para determinar dicha vocación como alta, media o baja en cada indicador, como lo muestra el cuadro 2 .

Cuadro 2. Puntuaciones para determinar la vocación turística de los recursos y atractivos turísticos

\begin{tabular}{|l|l|l|l|}
\hline \multirow{2}{*}{ INDICADOR } & \multicolumn{2}{c|}{ GRADO DE INCIDENCIA } \\
\cline { 2 - 4 } & Baja & \multicolumn{1}{|c|}{ Media } & \multicolumn{1}{c|}{ Alta } \\
\hline $\begin{array}{l}\text { Clima: toma en cuenta cambios por la estacionalidad de } \\
\text { las lluvias y efectos de la temperatura en las actividades a } \\
\text { realizar }\end{array}$ & 0 & 1 & 2 \\
\hline $\begin{array}{l}\text { Esfuerzo físico: considera la duración, complejidad o tipo } \\
\text { de esfuerzo y grado de condición física que demanda el } \\
\text { atractivo y actividad a realizar }\end{array}$ & 2 & 1 & 0 \\
\hline $\begin{array}{l}\text { Seguridad: considera las características físicas del atractivo } \\
\text { y la existencia de construcciones como barandas, escaleras, } \\
\text { equipamiento, otros }\end{array}$ & 2 & 1 & 0 \\
\hline $\begin{array}{l}\text { Facilidades: valora la necesidad de que el atractivo cuenta } \\
\text { con algún tipo de facilidad requerida }\end{array}$ & 2 & 1 & 0 \\
\hline $\begin{array}{l}\text { Dificultad de Acceso: considera las características } \\
\text { topográficas para llegar al atractivo }\end{array}$ & 0 & 1 & 2 \\
\hline $\begin{array}{l}\text { Diversidad: valora las diferentes actividades que pueden } \\
\text { realizarse en el lugar }\end{array}$ & 2 & 1 & 0 \\
\hline \multicolumn{1}{|c|}{ VOCACIÓN TURÍSTICA } & \multicolumn{2}{|c|}{ PUNTUACIÓN } \\
\hline Baja & \multicolumn{3}{|c|}{0 a 0,66} \\
\hline Media & \multicolumn{2}{|c|}{1,34 a 2,00} \\
\hline Alta & & 1,33 \\
\hline
\end{tabular}

Fuente: Flores (2009) adaptado de Morera (2007) 
En esta ficha de evaluación se representan el nivel de incidencia de los indicadores para cada recurso, en tres categorías, donde 0 es baja incidencia, 1 incidencia media y 2 alta incidencia. Una vez que se asignan estos valores de incidencia (de 0 a 2) para cada factor se aplica la fórmula de ponderación: Valor Ponderado de Factores (VPFI): $\sum$ valores de las variables / número de variables. El cuadro 3, muestra cómo se representan los resultados del valor ponderado de la evaluación del potencial, en relación con la incidencia.

Tomando en cuenta que son tres los niveles de incidencia, se crean tres intervalos 0,66 puntos, para poder ubicar los resultados como alto, medio o bajo. Este valor se obtiene al dividir el máximo valor de incidencia (2) entre $3(2 / 3: 0,66)$. Los valores determinados por estas fórmulas se clasifican en el cuadro 4 , donde presenta las puntuaciones que determinan la incidencia; siesta es baja el potencial turístico es alto y si es alta el potencial será bajo.

Para efectos de esta investigación se utiliza la metodología de análisis de incidencia de factores, porque permite calificarla de manera participativa, según los indicadores establecidos en el cuadro 2. 
Marlene Lizette Flores-Abogabir, Meylin Alvarado-Sánchez. El sistema turístico de la comunidad de Copal, Nicoya, Guanacaste, Costa Rica. Un diagnóstico participativo
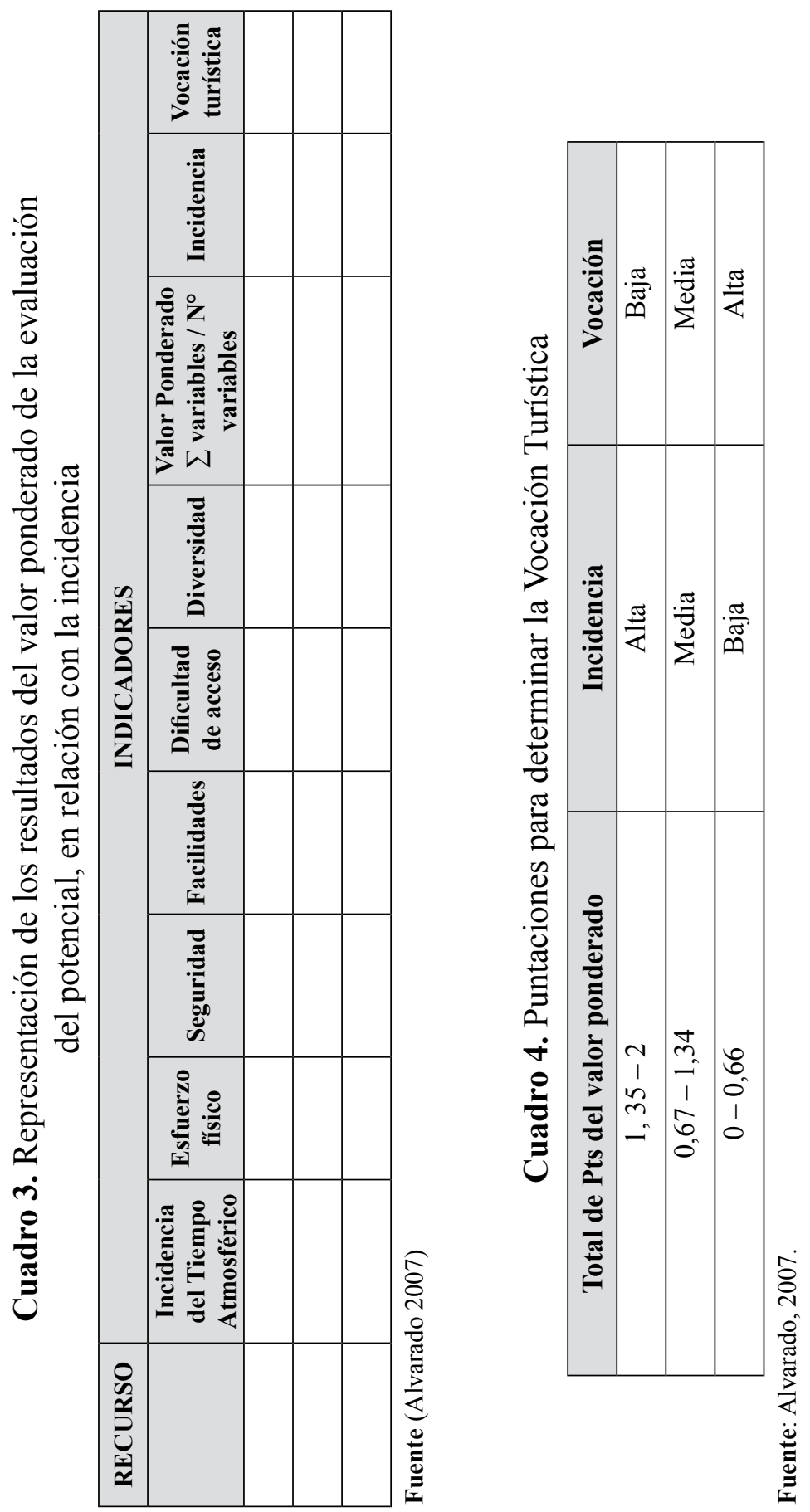
El cuadro 5 muestra la lista de recursos y/o atractivos turísticos según la valoración de la vocación turística en la comunidad de estudio.

Cuadro 5. Comunidad de Copal: Valoración de la vocación turística

\begin{tabular}{|l|c|c|c|}
\hline $\begin{array}{c}\text { RECURSOS y/o ATRACTIVO } \\
\text { TURÍSTIO }\end{array}$ & $\begin{array}{c}\text { PUNTAJE TOTAL } \\
\text { GRADO DE } \\
\text { INCIDENCIA }\end{array}$ & $\begin{array}{c}\text { VALOR } \\
\text { PROMEDIO }\end{array}$ & $\begin{array}{c}\text { VOCACIÓN } \\
\text { TURISTICA }\end{array}$ \\
\hline Feria cultural copaleña & 10 & 1,67 & Alta \\
\hline $\begin{array}{l}\text { Otros acontecimientos } \\
\text { programados: turnos, ferias } \\
\text { patronales }\end{array}$ & 10 & 1,67 & Alta \\
\hline Comunidad de Copal & 10 & 1,67 & Alta \\
\hline $\begin{array}{l}\text { Zona arqueológica y cementerio } \\
\text { indígena }\end{array}$ & 8 & 1,33 & Media \\
\hline Salineras & 7 & 1,17 & Media \\
\hline Estero Letras & 7 & 1,17 & Media \\
\hline Puerto Carazo y Pochote & 6 & 1,17 & Media \\
\hline Catarata El Salto & 6 & 1,00 & Media \\
\hline Playa Conchita & 6 & 1,00 & Media \\
\hline Golfo de Nicoya y manglares & 5 & 1,00 & Media \\
\hline Río Tempisque y Nacientes & 2 & 0,83 & Media \\
\hline $\begin{array}{l}\text { Cerros y Miradores de Copal: } \\
\text { Carazo, Sombrero, La Palma, la } \\
\text { Tigra, Las Pozas y Pochote }\end{array}$ & & & \\
\hline $\begin{array}{l}\text { Cavernas: Cerro La Tigra y Cerro } \\
\text { Las Pozas }\end{array}$ & & & Baja \\
\hline
\end{tabular}

Fuente: Flores, 2009, p.82

\section{Segmentación de la demanda turística}

La segmentación del mercado se puede definir como el proceso mediante el cual, una empresa subdivide un mercado en subconjuntos de clientes de acuerdo a ciertas características que le son de utilidad. (Thompson, 2005). El análisis de segmentación de la demanda en esta investigación, consiste en definir las características específicas de los compradores potenciales, que los distinguen de otros, dentro de la diversidad de turistas que se encuentran a nivel global.

En esta investigación, se propuso definir al posible consumidor de este tipo de turismo. Las siguientes interrogantes permitieron orientar la 
definición del mercado meta, esto es aquel perfil de visitante que interesa atraer para que consuma los productos y servicios del Proyecto de TRC de Copal de Nicoya: ¿De cuáles países provienen los potenciales compradores de TRC?, ¿Qué necesidades tienen?, ¿Cuáles son sus valores?, ¿Qué intereses pueden tener?, ¿Cuál es su nivel adquisitivo?, ¿A través de qué canales de comunicación y / o de venta contactan sus destinos?, ¿Cómo viajan?, ¿Cuántos días se quedan en Costa Rica?, ¿Qué nivel educativo tienen?

Según el Estado de la Nación (2007), Costa Rica en los últimos 20 años, experimentó un acelerado desarrollo turístico, constituyendo al turismo como una de las principales actividades económicas del país; lo cual fue posible por el posicionamiento de una "marca país" en el mercado internacional, entendida ésta como la imagen que las autoridades públicas y los operadores privados han proyectado en el resto del mundo con el fin de promocionar a Costa Rica como destino turístico distinto. Para el caso de Costa Rica, mediante campañas publicitarias la "marca país" se ha asociado con valores y prácticas como democracia, paz, seguridad, conservación y manejo sostenible de los recursos naturales. La determinación del posicionamiento deseado debe ser congruente con esta "marca país" y con el legado histórico, cultural y arqueológico y la diversidad de paisajes naturales que posee la comunidad.

Para Morera (Op cit), la realización de estudios para determinar el perfil del visitante o estudios de segmentación, es uno de los componentes fundamentales del sistema turístico porque permiten caracterizar y conocer el tipo de personas que visitan un destino. Esto es primordial para ajustar mejor la oferta turística y procurar, con ello, una mayor satisfacción por parte de los visitantes. Para identificar el perfil de la demanda, la evidencia se obtiene a través de la organización de mujeres y ejecución de las "Ferias Culturales Copaleñas", así como de guías turísticos y entrevistas a actores locales y expertos (a algunos de ellos se les aplicó entrevistas abiertas), que permiten caracterizar al visitante que han contratado estos servicios turísticos de acuerdo con la siguiente información:

- $\quad$ Procedencia. España, y grupos de académicos y estudiantes de la UNA.

- Género. Anivel internacional, todos los turistas que visitaron la comunidad fueron hombres. A nivel nacional $60 \%$ hombres y $40 \%$ mujeres. 
- Acompañante. Los turistas internacionales viajan en grupos que hacen pruebas de vehículos de la marca Toyota y que gustan de actividades culturales; y a nivel nacional viajan en grupos de académicos y estudiantes de la UNA.

- Medio por el que llegaron. Los turistas internacionales llegaron en vuelo charter al aeropuerto Daniel Oduber y en carros de la Toyota hasta la comunidad. Los turistas nacionales llegaron en autobús contratado para tal fin.

- Estadía. Los turistas internacionales permanecen en la comunidad aproximadamente 3 horas y media, que es la duración de la Feria Cultural Copaleña. Por su parte, los nacionales permanecieron un día y medio.

- $\quad$ Actividades realizadas e intereses. Los turistas internacionales realizan las actividades que se incluyen en la Feria Cultural, como degustación de platos propios de la zona y actividades culturales, tales como bailes típicos, desfile de carretas y el espectáculo de monta de toros. Se destaca que los turistas nacionales, contemplaron, además, una lunada y caminata dirigida por algunos sitios.

- Organización del viaje. A nivel internacional, el viaje es organizado a través de la Agencia Rutas Tropicales. A nivel nacional, a través del programa y unidades académicas de la UNA.

- Organización del paquete. De acuerdo con los informes de las ferias desarrolladas, los turistas internacionales organizaron su viaje a la comunidad de Copal por medio de un paquete turístico, a través de operadores. Los nacionales, organizaron su viaje directamente con la organización comunal que oferta el servicio.

En forma paralela, esta iniciativa de TRC en Copal, debe considerar otro mercado meta, a nivel nacional constituido por organizaciones tales como instituciones públicas y privadas que requieren de efectuar actividades especiales como reuniones, seminarios, congresos y otras. También grupos de estudiantes, congregaciones religiosas, grupos deportivos, entre otros. A nivel internacional, estar dirigido a turistas captados por otros destinos como hoteles de la zona, los cuales consideren la oferta de Copal como un complemento de sus actividades. La importancia de considerar un segundo tipo de mercado meta se fundamenta en la necesidad de 
gestionar la demanda en temporada baja de turismo internacional, para procurar el óptimo aprovechamiento de la capacidad instalada y organizativa del proyecto.

\section{Conclusiones}

La comunidad de Copal presenta una situación que hace necesaria la implementación de alternativas económicas productivas, para buscar el mejoramiento de las condiciones de vida de su población.

Los resultados de esta investigación, demuestran que esta comunidad tiene potencialidades para desarrollar una propuesta de TRC, que se basan en la integración de los recursos y atractivos turísticos con la vida cotidiana de la comunidad de Copal, a través de prácticas productivas sostenibles y la integración de la población local en la actividad empresarial, con actores locales entre los que sobresalen organizaciones de base comunitaria, familias, grupos de mujeres y jóvenes guías. Entre esas potencialidades, la comunidad cuenta con más de diez recursos naturales, socioculturales e históricos, que muestran vocación turística y pueden incorporarse en un producto turístico local. Además, en la comunidad se han identificado una serie de organizaciones que fortalecen la gestión de la actividad turística. A pesar de todas estas potencialidades, se reveló que la oferta turística es limitada, la demanda es baja y hay poca comercialización, lo cual puede mejorarse si se toman en cuenta los procesos de encadenamiento de los operadores locales en esta actividad.

\section{Referencias}

Alvarado, M. (2007). Propuesta Para El Fortalecimiento Del Producto Turístico Comunitario En Costa De Pájaros, Puntarenas. Proyecto de Maestría Profesional en Desarrollo Comunitario Sustentable. Heredia, UNA.

Flores, M. (2009). El Turismo Rural Comunitario: Una alternativa productiva para la comunidad de Copal, Quebrada Honda de Nicoya, Guanacaste. Tesis de Maestría en Desarrollo Rural. Heredia, UNA.

Flores, M., Alvarado, M. y Padilla, A. (2008). Diagnóstico Participativo del Sistema Turístico de las Comunidades Aledañas al Golfo de Nicoya. Ponencia Presentada en IV Congreso Mesoamericano de Estudios Turísticos, Campus Nicoya, Sede Regional Chorotega, UNA. 
Morera, C. (2006). Concepto y realidad del turismo rural en Costa Rica. Revista Ambientico, No ${ }^{\circ}$ 50. Heredia, UNA.

Morera, C. (2007). Guión del Curso: Turismo Rural. Maestría de Desarro1lo Comunitario Sustentable. Heredia: Universidad Nacional.

Programa Estado de la Nación (Costa Rica-2007). Decimotercer Informe Estado de la Nación en Desarrollo Humano Sostenible. San José Costa Rica.

Sancho, A. (1998). Introducción al Turismo. Organización Mundial del Turismo (OMT). Madrid, España.

Thompson, I. (2005). La segmentación del mercado. Recuperado de: http://www.promonegocios.net/mercadotecnia/segmentacion-delmercado.htm

\section{Entrevistas}

Padilla, Guadalupe. (2009). Entrevista Personal Abierta, Presidenta Asociación de Mujeres, Copal de Nicoya. Período 2008-2009

Reyes, Narciso. (2009). Entrevista Personal Abierta, Presidente ASADA de Pochote, Copal de Nicoya.

Villegas, José Raúl. (2008). Entrevista personal abierta, guía turístico de la comunidad de Tortuguero. 